\title{
Autonomia: viver a própria vida e morrer a própria morte
}

\author{
Autonomy: to live one's own life \\ and to die one's own death
}

\begin{abstract}
1 Promotoria de Justiça Criminal de Defesa dos Usuários dos Serviços de Saúde, Ministério Público do Distrito Federal

e Territórios, Brasília, Brasil.

Correspondência D. C. Ribeiro Promotoria de Justiça Criminal de Defesa dos Usuários dos Serviços de Saúde, Ministério Público do Distrito Federal e Territórios. Eixo Monumental, Praça do Buriti, Lote 2, Sala 507, Brasília, DF 70094-900, Brasil. diaulas@diaulas.com.br
\end{abstract}

\begin{abstract}
The present study describes the changes that have occurred in most Western countries, Brazil included, since medicine has shifted progressively from a paternalistic model to one that promotes patients autonomy and self-determination. Respect for patient autonomy and self-determination is the primary basis for withholding and withdrawing life support. An adult patient who has decision-making capacity and is appropriately informed has the right to forgo all forms of medical therapy, including life support measures. The right to refuse treatment applies equally to withholding therapy that might be offered, such as cardiopulmonary resuscitation, and to withdrawing therapy that is already underway, such as artificial hydration, nutrition, and ventilation. This right is based on the ethical principle of autonomy or self-determination. Helping an informed and capable patient to forgo life support under these circumstances is regarded as distinct from participating in requested homicide, assisted suicide, or passivelactive euthanasia. The patient has the right to choose, including where the deathbed will be placed, and to be left alone with family at that time.
\end{abstract}

Personal Autonomy; Assisted Suicide; Euthanasia; Bioethics
Diaulas Costa Ribeiro ${ }^{1}$

A palavra autonomia, do Grego autos (próprio) e nomos (regra, autoridade ou lei), foi utilizada, originariamente, para expressar o autogoverno das cidades-estado independentes. Na década de 1970 - tomamos como referência o Relatório Belmont -, incorporou-se à biomedicina para significar atribuição de poder para se tomar decisões sobre assuntos médicos. Comparativamente, uma pessoa com autonomia plena tem os mesmos poderes e garantias que um Estado: autodeterminação.

O Relatório Belmont, de 1978, foi apresentando pela National Comission for the Protection of Human Subjects of Biomedical and Behavioral Research, instituída pelo Governo americano, em 1974, "com o objetivo de levar a cabo uma pesquisa e um estudo completo que identificassem os princípios éticos básicos que deveriam nortear a experimentação em seres humanos nas ciências do comportamento e na biomedicina" 1 (p. 10). Nele, foram identificados três princípios éticos básicos: autonomia, beneficência e justiça.

As relações de saúde, construídas sob o modelo paternalista, foram diretamente afetadas pelo princípio da autonomia. No Brasil, a mudança ainda não está consolidada, mas há sinais indicativos da substituição do paternalismo pelo consentimento livre e esclarecido. Fala-se, hoje, em empowerment health, apoderamento sobre a saúde, ou seja, o paciente conquistou o poder de tomar decisões sobre sua 
saúde e sua vida; de sujeito passivo passou a titular do direito. O profissional de saúde, o médico por todos, de sujeito ativo passou a titular de uma obrigação. Antes soberano para tomar decisões clínicas, passou a conselheiro, num diálogo franco com o paciente, titular do direito de tomá-las mediante esclarecimento que lhe é devido pelo profissional.

A nossa legislação já contempla o respeito à autonomia do paciente. Mas o Novo Código Civil brasileiro, com suas três décadas de gestação, ainda usa expressões paternalistas, demonstrando que não foi assimilado o "neologismo". Confira-se o art. 13, que diz: "salvo por exigência médica, é defeso o ato de disposição do próprio corpo, quando importar diminuição permanente da integridade física, ou contrariar os bons costumes". Não existe mais exigência médica. A autonomia deu lugar à indicação, à recomendação, à prescrição, afastando a exigência, a ordem. No art. 15, ocorreu o mesmo: "ninguém pode ser constrangido a submeter-se, com risco de vida, a tratamento médico ou a intervenção cirúrgica", permitindo-se concluir que há obrigação de aceitar tratamento ou cirurgia sem risco de vida, o que seria, hoje, um contra-senso ético e jurídico. A leitura desse artigo "conforme a Constituição" deve ser: ninguém, nem com risco de vida, será constrangido a tratamento ou a intervenção cirúrgica, em respeito à sua autonomia, um destacado direito desta Era dos Direitos.

A autonomia não dispensa a capacidade para expressá-la. Há situações em que o paciente se torna incapaz de decisões instantes, como nos estados de inconsciência em geral, justificando o surgimento dos testamentos vitais $\mathrm{e}$ das diretivas antecipadas, instrumentos de manifestação de vontade para o futuro, com a indicação negativa ou positiva de tratamentos e assistência médica.

Esses testamentos são usados para tratar da assistência ao paciente terminal; as diretivas são utilizadas para dispor dos tratamentos médicos em geral, dos quais se pode recuperar ou não. Há, portanto, continência entre os institutos, não se justificando distingui-los 2 . Adotamos diretivas antecipadas que têm, pelo menos, quatro alternativas para materializar-se: escritura pública em cartório; declaração escrita em documento particular, de preferência com firma reconhecida; declaração feita ao médico assistente, registrada no prontuário, com a assinatura do paciente. Em qualquer situação, poderá haver a nomeação de um procurador para tomar decisões não incluídas nas diretivas.

A quarta alternativa se refere ao paciente que não elaborou diretivas antecipadas, mas que declarou a amigos e familiares sua rejeição ao esforço terapêutico nos casos de estado vegetativo permanente ou de doença terminal: trata-se de justificação testemunhal dessa vontade. Essa via, contudo, demanda processos judiciais longos, como ocorreu com Karen Quinlan, Nancy Cruzan e Terri Schiavo. Por sinal, nos dias de exposição do Caso Terri Schiavo, insistiu-se na supremacia do direito de viver, quando o caso indicava a necessidade de debater-se o direito de morrer, o direito autônomo de deliberar sobre o tempo e o lugar da própria morte.

O direito de viver não é antagônico ao direito de morrer: compreende, na verdade, duas dimensões de um mesmo direito. Aliás, o direito de viver já foi, inclusive, objeto de atual consideração da Igreja Católica, a Declaração sobre a Eutanásia (Sagrada Congregação para a Doutrina da Fé. Cidade do Vaticano; 1980): "de fato, há quem fale de 'direito à morte', expressão que não designa o direito de se dar ou mandar provocar a morte como se quiser, mas o direito de morrer com toda a serenidade, na dignidade humana e cristã".

O sistema jurídico brasileiro assegura o direito de viver e, dentro daquela aparente contradição, não reconhece formalmente o direito de morrer, o que levou a doutrina jurídica a afirmar equivocadamente que não há esse direito entre nós. Viver a vida com autonomia é um direito potestativo, que pode ser exercido sem qualquer anuência de terceiros; ninguém precisa de licença de outrem para viver a sua própria vida, mormente em países sem pena de morte. Feita essa exceção, ninguém, nem mesmo o Estado, pode impor qualquer restrição a esse direito, razão para se chamá-lo supremo.

Essa conclusão não afasta uma releitura do direito de viver, que, por ser direito potestativo, é renunciável apenas pelo seu titular. E se não fosse renunciável, não seria direito, mas dever de viver. E enquanto dever de viver geraria conseqüências jurídicas distintas das que hoje são conhecidas, começando pela punição da tentativa de suicídio, passando pela proibição dos esportes radicais e atividades de risco em geral e culminando na mecanização da vida para além da vida, o que imporia tratamentos desumanos e degradantes ao doente.

Alemanha e Portugal, dois sistemas jurídicos paradigmas para o Brasil, têm, como nós, punição para o homicídio. Têm, diferentemente de nós, um crime chamado homicídio a pedido da vítima, punido com uma pena simbólica se comparada com o homicídio tradicional. Em Portugal, quem mata determinado por pedido sério, instante e expresso da vítima é punido com pena de 1 mês a 3 anos, enquanto 
o homicídio qualificado pode chegar a 25 anos de prisão. Na Alemanha, quem mata a pedido da vítima é punido com pena de 6 meses a 5 anos de prisão, enquanto o homicídio qualificado pode ser punido com prisão perpétua.

O homicídio a pedido da vítima tem a característica de ser um crime punido apenas quando a morte decorre de uma ação, de uma conduta positiva, de um fazer algo. Não há crime quando o pedido é negativo, para não se fazer algo, com exceção apenas para os casos de suicídio, em que não se aceita a omissão de tratamentos vitais a pedido do suicida socorrido.

Isso quer dizer que a omissão de tratamentos médicos a pedido ou por recusa do doente não suicida não constitui crime e não se confunde com o homicídio a pedido da vítima nem pode ser chamado de eutanásia passiva. Muito pelo contrário, não respeitar o direito de morrer, o direito à autodeterminação, é constrangimento ilegal, pode ser abuso de poder e até lesão corporal, na opinião de Claus Roxin 3 (p. 23): "se o paciente recusa a operação que salvaria sua vida, ou a necessária internação numa unidade de tratamento intensivo, deve o médico abster-se de tais medidas e, se for o caso, deixálo morrer. Esta solução é deduzida, corretamente, da autonomia da personalidade do paciente, que pode decidir a respeito do alcance e da duração de seu tratamento". Em outras palavras, o dever de cuidado, que decorre da relação do paciente com o seu garante, seja ele médico ou não, cessa com a oposição ao cuidado, feita autonomamente pelo doente ou seu representante legal: pais, tutor, curador ou um procurador nomeado em diretivas antecipadas.

A propósito - e também para a devida comparação com o art. 15 do Código Civil-, o Código Penal brasileiro tratou do tema: "Art. 146. Constranger alguém, mediante violência ou grave ameaça, ou depois de lhe haver reduzido, por qualquer outro meio, a capacidade de resistência, a não fazer o que a lei permite, ou a fazer o que ela não manda. (...) \$ $30-N a ̃ o$ se compreendem na disposição deste artigo: I - a intervenção médica ou cirúrgica, sem o consentimento do paciente ou de seu representante legal, se justificada por iminente perigo de vida; II - a coação exercida para impedir suicídio...”. As exceções feitas nesse parágrafo terceiro significam que o médico não está obrigado a tomar essa medida. Mas, se a tomar, não praticará crime, o que demonstra o resquício do paternalismo o médico decide - inerente à época da elaboração do Código Penal, em vigência desde 1942.

Ainda a título de ilustração, o art. 128, do mesmo Código Penal, diz que "não se pune o aborto praticado por médico: I - se não há outro meio de salvar a vida da gestante; II - se a gravidez resulta de estupro e o aborto é precedido de consentimento da gestante ou, quando incapaz, de seu representante legal". A doutrina brasileira afirma há 60 anos que, na primeira hipótese, o médico não precisa de consentimento livre e esclarecido da mãe, sendo exclusivamente sua a decisão de interromper a gravidez nesses casos, o que viola todos os novos princípios éticos e as garantias jurídico-constitucionais incorporadas à nossa ordem jurídica a partir do reconhecimento, dentre outros, do direito à autonomia como inerente à dignidade humana. "Mas como é? Em qualquer situação, mas especialmente nesta situação ético-existencial, em que se trata de decidir sobre a morte ou a vida de um filho (ainda que em formação na "barriga" da mãe), vai prevalecer a vontade do médico sobre a [vontade] da mãe? E não é a liberdade consciente da mãe uma manifestação essencial da sua dignidade humana? Mais: vai ser o médico o juiz dos interesses (que não são econômicos!...) da mãe? Sobre essas considerações, não posso deixar de dizer apenas isto: pobres garantias individuais. Só se fosse uma ordem jurídica nazista; ai de nós se prevalecesse esta orwelliana república dos médicos!" 4 (p. 225).

$\mathrm{O}$ pedido instante ou a recusa a tratamentos em geral, feita por diretivas antecipadas, denomina-se Suspensão de Esforço Terapêutico (SET). Como o nome indica, trata-se de suspensão de tratamentos - incluindo nutrição, hidratação e respiração artificiais - que visam apenas a adiar a morte, em vez de manter a vida. A finalidade da SET é afastar um obstáculo para que a morte, naturalmente, instale-se; é suspender a obstinação terapêutica, a distanásia, a insistência tecnológica em "vencer o fim", como se isso fosse possível e atendesse ao melhor interesse do doente.

Essa conclusão também foi adotada pela Igreja Católica na Declaração sobre a Eutanásia: "na iminência de uma morte inevitável, apesar dos meios usados, é lícito em consciência tomar a decisão de renunciar a tratamentos que dariam somente um prolongamento precário e penoso à vida, sem contudo, interromper os cuidados normais devidos ao doente em casos semelhantes. Por isso, o médico não tem motivos para se angustiar, como se não tivesse prestado assistência a uma pessoa em perigo...". Mas, desde 24 de fevereiro de 1957, já havia referência, nos discursos do Papa Pio XII, à licitude da recusa a tratamentos extraordinários: " $a$ razão natural e a moral cristã fundamentam, ambas, o direito e o dever de, em caso de doença grave, procurar o tratamento para conservar a saúde e a vida. Normalmente alguém está obrigado a 
empregar apenas os meios ordinários - conforme as circunstâncias de pessoas, tempos e cultura -, isto é, meios que não impliquem ônus extraordinário para si ou para outrem. Obrigação mais severa seria por demais onerosa para a maioria das pessoas e tornaria muito difícil a consecução do bem superior, mais importante. Vida, saúde, todas as atividades temporais estão na realidade subordinadas aos fins espirituais" 5 (p. 147).

No Brasil, não há autorização legal para a eutanásia nem para o suicídio assistido. Por sinal, na Alemanha, não é crime a participação em suicídio, cuja punição, entre nós, tem pouca lógica jurídica, estando sustentada pela conveniência de uma política criminal influenciada pelo Código Canônico, que previa, até 1982, punições para os suicidas. Antes mesmo da revogação das punições aplicadas aos suicidas, que eram basicamente a proibição de celebração fúnebre religiosa e o sepultamento em cemitérios católicos, a Igreja já havia compreendido que a exigência de suspensão de esforço terapêutico feita pelo paciente não se confundia com suicídio 4 .

Mas a suspensão de esforço terapêutico tem suporte entre nós na Constituição Federal (art. 1.o, III, e art. 5.o, III) - que reconhece a dignidade da pessoa humana como fundamento do estado democrático brasileiro e diz expressamente: ninguém será submetido a tortura nem a tratamento desumano ou degradante -, no Código Civil (art. 15) - que autoriza o paciente a recusar determinados procedimentos médicos -, na Lei Orgânica da Saúde (Lei n. 8.080/90, art. 7.o, III) - que reconhece o direito à autonomia do paciente - e no Código de Ética Médica - que repete esses mesmos princípios legais e ainda proíbe o médico de realizar procedimentos terapêuticos contra a vontade do paciente, fora de um quadro de emergência médica de salvação, o que não é o caso de um quadro irreversível, sem nenhuma resposta a qualquer tipo de tratamento.

Há, ainda, uma lei excepcional sobre esse tema: a Lei dos Direitos dos Usuários dos Serviços de Saúde do Estado de São Paulo (Lei $n$. 10.241/99), conhecida como Lei Mário Covas, que assegura em seu art. 20: "são direitos dos usuários dos serviços de saúde no Estado de São Paulo: XXIII - recusar tratamentos dolorosos ou extraordinários para tentar prolongar a vida".

Ressalte-se, como a vida, que a morte digna também é um direito humano. E por morte digna se compreende a morte sem dor, sem angústia e de conformidade com a vontade do titular do direito de viver e de morrer. E nesse sentido é paradoxal a postura social, muitas vezes emanada de uma religiosidade que a religião des- conhece, que compreende, aceita e considera "humano" interromper o sofrimento incurável de um animal, mas que não permite, com o mesmo argumento - obviamente sem a metáfora - e nas mesmas condições, afastar o sofrimento de um homem capaz e autônomo. É interessante notar, ainda, que, enquanto se discute sem consenso a aceitação da eutanásia como um ato de cuidado, outros movimentos se desenvolvem e constroem soluções a partir de princípios que também são invocados naquela discussão: a autonomia e a dignidade no fim da vida.

Como resultado desses movimentos, o Ministério da Saúde editou a Portaria n. 675/GM de 30 de março de 2006, aprovando a Carta dos Direitos dos Usuários da Saúde, consolidando, num documento único, os direitos e deveres do exercício da cidadania na saúde em todo o Brasil. Nota-se, nesse documento, que o uso da palavra usuário - em vez de paciente, o sujeito passivo - não foi uma opção lingüística neutra, mas um passo decisivo para consolidar, no sistema de saúde nacional, a prevalência do interesse do doente e não mais do profissional de saúde. Em outras palavras, trata-se de iniciativa histórica a afirmar o consentimento livre e esclarecido como substituto do paternalismo nas relações de saúde, garantindo ao usuário o direito à informação a respeito de diferentes possibilidades terapêuticas de acordo com sua condição clínica, considerando as evidências científicas e a relação custo-benefício das alternativas de tratamento, com direito à recusa.

Essa portaria reafirmou que é direito do usuário o consentimento ou a recusa de forma livre, voluntária e esclarecida, depois de adequada informação, a quaisquer procedimentos diagnósticos, preventivos ou terapêuticos, salvo se isso acarretar risco à saúde pública. Também é direito do paciente revogar ou retratar, a qualquer momento, por decisão livre e esclarecida, o consentimento ou a recusa anteriores, sem que lhe sejam imputadas sanções morais, administrativas ou de qualquer natureza. São, ainda, direitos do usuário não ser submetido a nenhum exame, sem conhecimento e consentimento, bem como a indicação de um representante legal de sua livre escolha, a quem confiará a tomada de decisões para a eventualidade de tornar-se incapaz de exercer sua autonomia (direito de apresentar e de ter respeitadas suas diretivas antecipadas). Por fim, foi assegurado o direito de opção pelo local de morte, que contempla o direito de opção pelo tempo da morte. Esse direito atende à reivindicação da desospitalização do paciente, recusada por médicos sob o temor de estarem, com a alta a 
pedido, concorrendo para a morte do paciente, o que também é inerente ao paternalismo e já não tem razão de ser neste novo contexto.

Assim, morrer em casa é um valor que se resgata para escapar da solidão das UTIs, da engenharia médica de circunstância, da obstinação terapêutica e da indignidade no morrer. O direito de morrer a própria morte em casa ou onde se quiser morrer - é o direito sagrado de escolher onde, quando e com quem se quer fazer essa passagem, que são requisitos também feitos para o casamento, que é um dos mais antigos exemplos de respeito à autonomia $\mathrm{e}$ ao consentimento livre e esclarecido do nosso sistema jurídico.

Um exemplo recente ilustra e ajuda a compreender o que é morrer a própria morte. Consta-nos que o Papa João Paulo II decidiu deixar o hospital, onde provavelmente seria submetido a esforço terapêutico, para permanecer em casa, entre os seus, à espera da morte oportuna. Chamamos essa decisão de A Encíclica Silenciosa de Karol Wojtyla 6, que, como informado acima, havia aprovado, em 5 de maio de 1980, a Declaração sobre a Eutanásia, que tratou do que a Igreja considera e do que não considera eutanásia. Tratou do consentimento livre e esclarecido e da suspensão de esforço terapêutico, constituindo um documento básico para essa discussão, que, apesar de travar-se num Estado laico, não pode desconsiderar os aspectos religiosos que se apresentam no enfrentamento da morte. "É lícito, com o acordo do doente, recorrer aos meios de que dispõe a medicina mais avançada, mesmo que eles estejam ainda em fase experimental e não seja isenta de alguns riscos a sua aplicação. Aceitandoos, o doente poderá dar também provas de generosidade ao serviço da humanidade. É também permitido interromper a aplicação de tais meios, quando os resultados não correspondem às esperanças neles depositadas. Mas, para uma tal decisão, ter-se-á em conta o justo desejo do doente e da família, como também o parecer de médicos verdadeiramente competentes...". (Sagrada Congregação para a Doutrina da Fé. Declaração sobre a Eutanásia. Cidade do Vaticano; 1980).

Em conclusão, o respeito à autonomia, à autodeterminação pessoal é a base para a suspensão de esforço terapêutico dos usuários dos serviços de saúde. Por suspensão de esforço terapêutico compreende-se não iniciar ou suspender uma terapia iniciada, não ressuscitar nos casos de parada cardiorrespiratória, não submeter o doente à ventilação mecânica, alimentação e hidratação artificiais contra a sua vontade, que pode ser instante ou manifestada em diretivas antecipadas. Os médicos e demais profissionais de saúde têm o dever de respeitar a autonomia do usuário, inclusive para lhe dar alta "a pedido", deixando que a morte ocorra no local, no tempo e em companhia de quem o doente quiser. O usuário dos serviços de saúde tem o direito de estar só e de morrer só, de estar acompanhado e de morrer entre os seus 7 .

Por fim, Maquiavel classificou três tipos de inteligências humanas: a dos que entendem as coisas por si próprios; a dos que discernem o que os outros entenderam; e a dos que não entendem por si próprios nem sabem discernir o que os outros entenderam. Espera-se apenas que o direito de viver a própria vida e o direito de morrer a própria morte, enquanto primeiro e último dos direitos potestativos da personalidade, não fiquem à mercê desse último tipo de inteligência e que possam, pelas outras, ter a devida compreensão. Essa sempre foi a reivindicação dos que morreram antes de nós.

\section{Resumo}

Este estudo destaca mudanças ocorridas no Ocidente, inclusive no Brasil, em decorrência da substituição do princípio do paternalismo pelo consentimento livre e esclarecido nas relações biomédicas, com destaque para a integração da autonomia como princípio inerente à dignidade humana. O respeito à autonomia, à autodeterminação pessoal é a base para a suspensão de esforço terapêutico dos usuários dos serviços de saúde com capacidade preservada. Por suspensão de esforço terapêutico compreende-se não iniciar ou suspender terapia iniciada, não ressuscitar nos casos de parada cardiorrespiratória, não submeter o doente à ventila- ção mecânica, alimentação e hidratação artificiais contra a sua vontade, que pode ser instante ou manifestada em diretivas antecipadas. Os médicos e demais profissionais de saúde têm o dever de respeitar a autonomia do usuário, inclusive para lhe dar alta "a pedido", deixando que a morte ocorra no local, no tempo e em companhia de quem o doente quiser. O usuário dos serviços de saúde tem o direito de estar só e de morrer só, de estar acompanhado e de morrer entre os seus.

Autonomia Pessoal; Suicídio Assistido; Eutanásia; Bioética 
Referências

1. Beauchamp TL, Childress JF. Princípios de ética biomédica. São Paulo: Edições Loyola; 2002.

2. Gonzáles MAS. Um novo testamento: testamentos vitais e diretivas antecipadas. In: Bastos EF, Sousa AH, coordenadores. Família e jurisdição. Belo Horizonte: Del Rey; 2005. p. 91-137.

3. Roxin C. A tutela penal da vida humana. São Paulo: Editora Damásio de Jesus; 2005.

4. Carvalho AT. O conflito de deveres no exercício da medicina. Direito e Justiça, Lisboa 2004; XVIII: 215-40.

5. Pio XII. Allocuzione del 24.02.1957. Acta Apostolicae Sedis 1957; 49:147.

6. Ribeiro DC. Promotor do Distrito Federal quer garantir sexo para pacientes com paralisia cerebral [Entrevista]. Revista Época 2005; 365:22-6.

7. Queiroz A. Como vamos viver a morte? Jornal de Brasília 2004; 23 nov.

Recebido em 24/Abr/2006 Aprovado em 24/Abr/2006 